\title{
BMJ
}

\section{Improved survival at low lung function in cystic fibrosis: cohort study from 1990 to 2007}

\author{
P M George, academic registrar in respiratory medicine, ${ }^{1}$ W Banya, medical statistician, ${ }^{2} \mathrm{~N}$ Pareek, specialist \\ trainee in cardiology, ${ }^{1} \mathrm{D}$ Bilton, consultant respiratory physician and honorary senior lecturer, ${ }^{1,3} \mathrm{P}$ Cullinan, \\ professor of occupational and environmental respiratory disease, ${ }^{3} \mathrm{M}$ E Hodson, professor of respiratory \\ medicine, ${ }^{3,1} \mathrm{~N}$ J Simmonds, consultant respiratory physician ${ }^{1}$
}

\section{${ }^{1}$ Department of Cystic Fibrosis, Royal Brompton Hospital, London SW3 6NP, UK \\ ${ }^{2}$ Department of Research and Development, Royal Brompton Hospital \\ ${ }^{3}$ National Heart and Lung Institute, Imperial College London, London, UK \\ Correspondence: N Simmonds n.simmonds@rbht.nhs.uk}

Cite this as: $B M J$ 2011;342:d1008 doi:10.1136/bmj.d1008

\section{ABSTRACT}

Objectives To evaluate the survival of patients with cystic fibrosis whose lung function has deteriorated to a forced expiratory volume in one second $\left(\mathrm{FEV}_{1}\right)$ below $30 \%$ predicted in the recent treatment era and to explore factors associated with any change in survival.

Design Cohort study.

Setting Adult cystic fibrosis unit in London.

Participants 276 patients (147 (53\%) male) whose $\mathrm{FEV}_{1}$ was first observed to be less than $30 \%$ predicted between 1 January 1990 and 31 December 2003.

Main outcome measure Survival during follow-up to 31 December 2007 in two year sub-cohorts.

Results Median survival improved from 1.2 years in the 1990-1 group to 5.3 years in the $2002-3$ group, with a marked improvement in survival from 1994. The use of nebulised recombinant human DNase was significantly associated with a reduced risk of death (hazard ratio $0.59,95 \%$ confidence interval 0.44 to 0.79 ). Significantly increased risks were associated with a body mass index under 19 (hazard ratio $1.52,1.10$ to 2.10 ), long term oxygen therapy (3.52, 2.49 to 4.99), and nebulised antibiotics (1.84, 1.05 to 3.22).

Conclusion A marked improvement has occurred in the survival of patients with cystic fibrosis with an $\mathrm{FEV}_{1}$ less than $30 \%$ predicted. Secondary analyses suggest that some of this improvement may be due to use of recombinant human DNase.

\section{INTRODUCTION}

Cystic fibrosis is a multi-organ inherited disease characterised by chronic pulmonary infection, resulting in progressive airways disease with an inexorable decline in lung function. Overall, outcomes in cystic fibrosis are improving, and estimates made in the early 1990s that median life expectancy would double from 20 to 40 years of age are being realised. ${ }^{12}$ Whether this is also true for patients with late stage disease is less clear. On the basis of work by Kerem et al in 1992, a forced expiratory volume in one second $\left(\mathrm{FEV}_{1}\right)$ of less than $30 \%$ predicted has been generally accepted as the level of lung function at which median mortality within two years is greater than $50 \% .^{3}$ As a consequence, this threshold is widely used as an appropriate trigger for consideration of lung transplantation, ${ }^{4}$ although, more recently, predictive survivorship models have been developed to facilitate this process. ${ }^{5}$

In the past 20 years, several factors have contributed to preserving the lung function of patients with cystic fibrosis, and a threshold of $\mathrm{FEV}_{1}$ below $30 \%$ predicted may no longer have the same clinical relevance. A more developed understanding of the importance of nutrition and its relation to lung function has led to a greater emphasis on intensive nutritional management. ${ }^{67}$ Many new treatments have been developed during this time, including inhaled tobramycin, ${ }^{8}$ nebulised recombinant human DNase, ${ }^{9}$ hypertonic saline,${ }^{10}$ and azithromycin. ${ }^{11}$ Recombinant human DNase has been used widely since the mid1990s and has resulted in improved airway clearance, improved lung function, and fewer exacerbations. ${ }^{912}$ Non-invasive ventilation in chronic type 2 respiratory failure has been practised more extensively, including as a bridge to transplantation, to palliate troublesome symptoms of hypercapnoea, and possibly to extend life in patients with the lowest level of lung function. ${ }^{13} \mathrm{Mul}-$ tidisciplinary clinical teams in specialised cystic fibrosis centres have also contributed to improved care. ${ }^{14}$ Since the study by Kerem et al, evidence has emerged to show that median survival may not be as low as two years, ${ }^{15}$ especially if other clinical factors (such as rate of decline in lung function) are considered. ${ }^{16}$ However, no study has re-evaluated the survival of patients with cystic fibrosis whose lung function has deteriorated to an $\mathrm{FEV}_{1}$ below $30 \%$ predicted in the recent treatment era. We set out to do this, hypothesising that most patients with an $\mathrm{FEV}_{1}$ at this level are now surviving considerably longer than two years. ${ }^{3}$ As a secondary aim, we explored factors associated with any change in survival.

\section{METHODS}

Since 1965, details of all patients referred to the adult cystic fibrosis unit at Royal Brompton Hospital and confirmed to have cystic fibrosis have been systematically recorded; until 2003, information on 1358 
Table 1|Characteristics and measures of survival for each two year sub-cohort

\begin{tabular}{|c|c|c|c|c|c|c|c|}
\hline Year of sub-cohort & No & No (\%) male & $\begin{array}{l}\text { Mean (SD) } \\
\text { age (years) }\end{array}$ & $\begin{array}{l}\text { Mean (SD) FEV } \\
(\% \text { predicted) }\end{array}$ & $\begin{array}{l}\text { Total follow-up } \\
\text { (months) }\end{array}$ & $\begin{array}{l}\text { Median survival } \\
\text { (years) }\end{array}$ & $\begin{array}{l}\text { Crude hazard ratio } \\
\qquad(95 \% \mathrm{Cl})\end{array}$ \\
\hline 1990-1 & 33 & $19(58)$ & $27.2(10.1)$ & $23.0(5.5)$ & 107.8 & 1.2 & 1.00 \\
\hline $1992-3$ & 66 & $30(45)$ & $24.7(7.5)$ & $22.3(4.9)$ & 189.6 & 1.7 & 1.01 (0.66 to 1.56$)$ \\
\hline $1994-5$ & 44 & $24(55)$ & $25.6(5.6)$ & $24.6(4.2)$ & 182.9 & 3.8 & 0.60 (0.37 to 0.98$)$ \\
\hline $1996-7$ & 54 & $24(44)$ & $24.5(7.6)$ & $25.1(3.5)$ & 288.1 & 5.0 & $0.40(0.25$ to 0.65$)$ \\
\hline 1998-9 & 27 & $14(52)$ & $25.4(7.7)$ & $25.1(3.5)$ & 149.3 & 6.7 & $0.43(0.24$ to 0.76$)$ \\
\hline $2000-1$ & 22 & $14(64)$ & $29.2(10.0)$ & $23.7(4.3)$ & 100.1 & 4.0 & 0.37 (0.19 to 0.72$)$ \\
\hline $2002-3$ & 30 & $22(73)$ & $27.7(7.6)$ & $24.0(5.7)$ & 113.7 & 5.3 & $0.38(0.20$ to 0.71$)$ \\
\hline
\end{tabular}

$\mathrm{FEV}_{1}=$ forced expiratory volume in one second.

patients had been collected in this way. The diagnosis of cystic fibrosis was based on clinical features and a positive sweat sodium $(>70 \mathrm{mmol} / \mathrm{L})$ or chloride $(>60 \mathrm{mmol} / \mathrm{L})$ result or, in cases with a borderline or negative sweat test result, the presence of a known disease causing mutation on each CFTR gene or of an abnormal nasal potential difference measurement. Clinical and demographic details were collected at the first consultation and subsequently updated at annual review, during clinical stability.

We included in the study all such patients whose $\mathrm{FEV}_{1}$, during clinical stability, was first observed to be less than $30 \%$ of the predicted value for their height, sex, and age between 1 January 1990 and 31 December $2003,{ }^{17}$ and we examined their survival through to 31 December 2007. Deaths and the dates of death came from clinic records; in the 13 cases for which we could not verify vital status to the end of the study ("lost to follow-up"), we censored survival at the time of their last clinic attendance. We excluded patients who subsequently had lung transplantation $(n=77)$, as censoring their survival at the date of their operation would have introduced variations in survival. This is because the length of time spent on a transplant list is highly variable, as factors other than clinical severity are considered (for example, donor shortages and tissue matching).

At point of entry into the cohort, we collected information on age, sex, percentage of predicted $\mathrm{FEV}_{1}$, body mass index, sputum microbiology (chronic Pseudomonas aeruginosa and Burkholderia cepacia infection; two positive samples in the preceding six month period), pancreatic exocrine function status (use of pancreatic enzymes), diabetes status (cystic fibrosis related diabetes: positive oral glucose tolerance test and glucose monitoring), use of nebulised antibiotics (any), use of nebulised recombinant human DNase, use of long term oxygen therapy ( $>16$ hours a day), and use of non-invasive ventilation. We categorised patients as being underweight if their body mass index was below $19 .{ }^{18}$ All patients had given informed written consent for their anonymised clinical details to be used for research purposes.

\section{Statistical analysis}

We used Stata (version 10.1) statistical software to analyse data. We present categorical data with percentages and quantitative data by mean values with standard deviations. Before analysis, we elected to compare survival in two year sub-cohorts with estimates of median survival and by Kaplan-Meier survival curves. We derived unadjusted hazard ratios for death in each sub-cohort by using Cox's proportional hazards regression, having verified the proportionality of hazards by using an option in Stata that plots survival curves for each category of a covariate versus time analysis ("log-log" plots). The proportional hazards assumption is not violated when the curves are parallel, which was the case for our data.

We used a multivariate Cox regression model to examine clinical and demographic factors that might be associated with survival; we included in the model all factors that we thought relevant on clinical grounds, irrespective of their statistical effect on survival. As very few patients were regularly using non-invasive ventilation $(\mathrm{n}=2)$ or were chronically infected with $B$ cepacia $(\mathrm{n}=18)$, we did not include these factors in the survival model.

\section{RESULTS}

We analysed 276 patients, and table 1 summarises their characteristics. Overall, 53\% $(\mathrm{n}=147)$ were male; at entry to the cohort, the mean age was 25.9 (SD 7.9) years, the mean $\mathrm{FEV}_{1}$ was $23.9 \%(4.6 \%)$ of the predicted value, and $92.3 \%(n=253)$ of patients were taking pancreatic supplements.

Table 1 also shows measures of survival of patients in each two year sub-cohort. Median survival improved from 1.2 years in the 1990-1 sub-cohort to 5 .

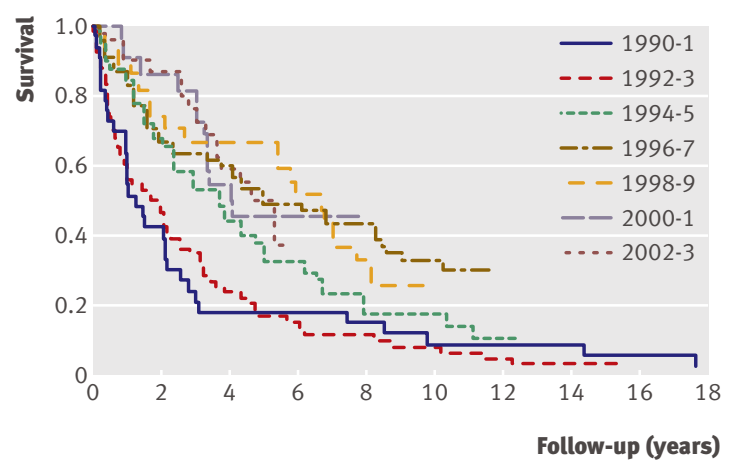

Fig 1 Kaplan-Meier survival curves subdivided into seven two year sub-cohorts from 1990 to 2003, showing survival up to 31 December 2007 
Table 2 | Multivariate Cox regression analysis of some measures of disease status and important treatment modalities at time of entry to cohort. Values are numbers (percentages) unless stated otherwise

\begin{tabular}{|c|c|c|c|c|c|c|}
\hline \multirow[b]{2}{*}{ Variable } & \multirow[b]{2}{*}{ Alive $(n=65)$} & \multirow[b]{2}{*}{ Dead $(n=211)$} & \multicolumn{2}{|c|}{ Univariate model } & \multicolumn{2}{|c|}{ Multivariate model* } \\
\hline & & & Hazard ratio $(95 \% \mathrm{Cl})$ & $P$ value & Hazard ratio $(95 \% \mathrm{Cl})$ & $P$ value \\
\hline Mean (SD) age (years) & $26.7(7.5)$ & $25.6(8.1)$ & $0.98(0.97$ to 1.00$)$ & 0.07 & $0.99(0.97$ to 1.01$)$ & 0.54 \\
\hline Male sex & $46(71)$ & $101(48)$ & $0.74(0.57$ to 0.98$)$ & 0.03 & 0.89 (0.66 to 1.18$)$ & 0.41 \\
\hline Body mass index <19 & $35 / 63(56)$ & $144 / 208(69)$ & $1.70(1.26$ to 2.29$)$ & $<0.001$ & $1.52(1.10$ to 2.10$)$ & 0.011 \\
\hline Pancreatic insufficiency & $56 / 65(86)$ & $197 / 209(94)$ & $1.63(0.91$ to 2.92$)$ & 0.10 & $0.91(0.46$ to 1.80$)$ & 0.79 \\
\hline Chronic Pseudomonas aeruginosa infection & $39 / 61(64)$ & $189 / 209(90)$ & 2.16 (1.39 to 3.37$)$ & 0.001 & $1.18(0.79$ to 1.76$)$ & 0.41 \\
\hline Cystic fibrosis related diabetes & $10 / 64(16)$ & $62(29)$ & 1.58 (1.78 to 2.13$)$ & 0.003 & $1.28(0.92$ to 1.79$)$ & 0.14 \\
\hline Use of recombinant human DNase & $50(77)$ & $111(53)$ & 0.57 (0.44 to 0.75$)$ & $<0.001$ & 0.59 (0.44 to 0.79$)$ & $<0.001$ \\
\hline Use of nebulised antibiotics & $43 / 60(72)$ & $177 / 211(84)$ & $2.22(1.40$ to 3.54$)$ & 0.001 & 1.84 (1.05 to 3.22$)$ & 0.033 \\
\hline Use of long term oxygen therapy & $2 / 62(3)$ & $60 / 207$ (29) & $4.47(3.27$ to 6.16$)$ & $<0.001$ & 3.52 (2.49 to 4.99$)$ & $<0.001$ \\
\hline
\end{tabular}

*Includes all variables listed in table.

3 years in the 2002-3 sub-cohort, with a marked improvement in survival from 1994 to 1997 but little change thereafter. This pattern is reflected in the unadjusted hazard ratios for each sub-cohort and in the survival curves shown in figure 1.

Figure 2 summarises, for each sub-cohort, some measures of disease status and important treatment modalities at the time of entry to the cohort; also included are the unadjusted hazard ratios for death in each sub-cohort. From 1994 onwards, a "step" increase occurred in the use of nebulised recombinant human DNase; across the entire study period a more gradual reduction occurred in the proportion of patients who were, at entry to the cohort, markedly underweight (body mass index $<19$ ). Other parameters, including the use of nebulised antibiotics and $P$ aeruginosa infection rates, remained stable over the 13 year period of study. The beginning of the improvement in survival coincided with the increase in the proportion of patients who were using recombinant human DNase at entry to the cohort.

Table 2 shows the modelled associations between survival and these parameters. In a multivariate model, the use of nebulised recombinant human DNase was significantly associated with a reduced risk of death (hazard ratio $0.59,95 \%$ confidence interval 0.44 to 0.79 ). Significantly increased risks were associated with a body mass index below 19 (hazard ratio $1.52,1.10$ to 2.10 ) and the use of both long term oxygen therapy $(3.52,2.49$ to 4.99$)$ and nebulised antibiotics $(1.84,1.05$ to 3.22$)$. After the inclusion of a binary term for entry into the cohort pre-1996/post-1995 (hazard ratio $0.62,0.43$ to 0.89 ), the use of recombinant human DNase was no longer significantly associated with improved survival $(0.78,0.55$ to 1.11$)$ but the other associations were essentially unchanged.

\section{DISCUSSION}

Our findings show an important improvement in the average survival of patients with cystic fibrosis whose lung function (forced expiratory volume in one second) has fallen below $30 \%$ of their predicted value. Median survival for patients who entered the cohort most recently (2002-3) was 5.3 years, more than twice that for those who entered the study in the early 1990s, when median survival was less than two years, similar to the value published by Kerem et al in $1992 .^{3}$ Interestingly, survival did not increase steadily over the period of our study; rather, an obvious stepwise improvement occurred from 1994 to 1997 with little further change thereafter. Over the same period, we recorded important changes in disease status and some treatment modalities. Nebulised recombinant human DNase first received a UK licence in 1994, which explains the striking increase in its use from this year; $80 \%$ of the subsequently enrolled cohort received it. A steady improvement in nutritional status also occurred, from $73 \%$ of patients underweight in 1990 to around $50 \%$ in the early 2000 s. Other parameters included in our study were relatively unchanged over this time.

\section{Comparison with other studies}

Since the study by Kerem et $\mathrm{al},{ }^{3}$ two other North American studies from the late 1990s have suggested that the median survival of patients with a forced expiratory volume in one second below 30\% predicted is better than two years, showing survival of at least 3.9 years in their centres. ${ }^{1516}$ Our study included a much larger study population, examining survival from 1990 for a further 17 years, thus incorporating a more contemporary era of management and treatment. A median survival of 5.3 years confirms a further step improvement and highlights the difficult challenge of determining when patients are genuinely "end stage" and should thus be referred for transplantation. This was also shown by a study that used predictive survivorship models and concluded that five year survival varied between $6 \%$ and $94 \%$ when forced expiratory volume in one second was below $30 \%$ predicted and that survival was superior for non-transplanted patients for the first 2.5 years of follow-up. ${ }^{5}$

An independent association of nebulised recombinant human DNase with improved survival was evident on regression analysis, which suggested that its use was related to a $41 \%$ reduction in mortality. Of the other treatments we examined, both were associated with an increase in mortality, presumably 
reflecting their use, at that time, in particularly sick patients. Our study is observational, and, as very few patients were prescribed recombinant human DNase before 1994 and almost all were after this date, disentangling its effects from other (unmeasured) factors with a temporal trend across the period of our study is statistically difficult. However, the ecological relation between the use of recombinant human DNase and the improvement in survival and the magnitude of its effect in the regression analysis are compelling observations. Nebulised recombinant human DNase has been shown in controlled trials to improve lung function, reduce pulmonary exacerbations, and modulate airway inflammation in cystic fibrosis, but it has not previously been shown to improve survival. ${ }^{919} \mathrm{~A}$ recent Cochrane systematic review also confirmed these findings. ${ }^{20}$ The rapidity with which survival improved after the widespread use of this treatment in our cohort is, in our view, biologically plausible, as studies of the drug have shown benefits on lung function from as early as one week and continuing up to two years..$^{91221}$

Underweight patients were at significantly greater risk of death; those whose body mass index was less than 19 at entry, a commonly used trigger for escalating nutritional intervention in cystic fibrosis, ${ }^{18}$ had an independent increase in mortality of $52 \%$. This finding supports a well established concept but importantly also shows its clinical significance when lung function is poor. Since the introduction of enteric coated pancreatic enzymes in the 1980s, huge progress has been made in the nutritional status of patients with cystic fibrosis. ${ }^{22}$ Other factors, including chronic infection with $P$ aeruginosa, cystic fibrosis related diabetes, and sex, were significant only on univariate analysis. The first two are widely accepted to be associated with a worse outcome in cystic fibrosis. ${ }^{623-25}$ Female sex has also been shown to have a deleterious effect, ${ }^{26}$ although some people argue that this is a reflection of confounding by other factors, such as a worse nutritional state. ${ }^{6}$

\section{Strengths and limitations of study}

We recognise several limitations to our study. Our patients were recruited from a single centre, and a

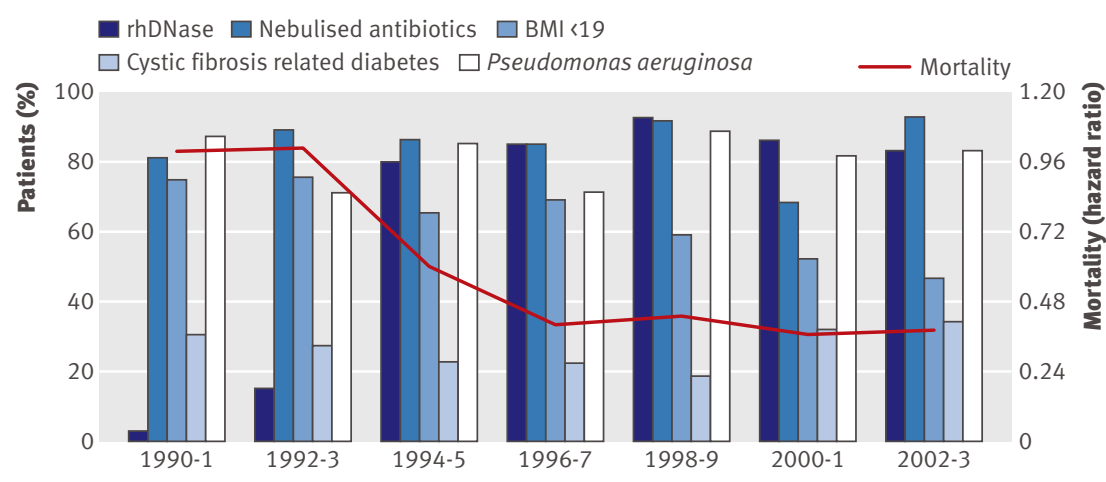

Fig 2 | Selected measures of disease status and important treatment modalities at time of entry to cohort shown as percentages, with corresponding unadjusted hazard ratios for death in each sub-cohort. BMI=body mass index small number were lost to follow up. Although we doubt that this detracts from the generalisability or accuracy of our findings, other cystic fibrosis centres need to examine survival in this population of especially sick patients. We examined determinants of survival only at entry to the cohort rather than during the period of follow-up. We did this because we wanted to consider the prognostic value of these factors at the point at which lung function fell below $30 \%$ predicted; in fact, a time dependent analysis would probably have made little difference to our findings, as most if not all of the variables we examined would be unvarying over time. We could not examine the benefits of treatments for cystic fibrosis such as azithromycin and hypertonic saline, as most of the cohort pre-dates their widespread use after the publication of large randomised controlled trials. ${ }^{1011}$ Hypertonic saline is an effective nebulised mucolytic, but unlike recombinant human DNase it cannot be said to lead to an improvement in lung function in the long term. ${ }^{27}$ Finally, for reasons given earlier, we excluded from analysis those patients in the cohort who had had lung transplantation. We considered whether changes in the selection of patients for transplant over the period of the study might have resulted in a non-transplant group with more favourable survival. We think that this is unlikely, as we know of no such systematic change in approach during the period of our study; moreover, the proportion of cohort patients who had transplantation fell steadily from $28 \%(\mathrm{n}=13)$ in the $1990-1$ sub-cohort to $14 \%$ $(n=5)$ in the final (2002-3) sub-cohort.

This study highlights the importance of, and necessity for, using well conducted observational methods in chronic medical conditions for which large prospective controlled trials with outcome measures such as mortality are almost impossible to do effectively. No interventional study in cystic fibrosis has yet shown a benefit on mortality, and even large trials in chronic obstructive pulmonary disease have been hampered by insufficient statistical power and have failed to reach their primary end point. ${ }^{28}$ We believe the systematic collection of patients' data through registries with carefully constructed analysis will continue to play a vital role in informing clinicians' practice and optimising patients' outcomes.

\section{Conclusions and policy implications}

The implications of our study are several. Short of developing a cure for cystic fibrosis, improved survival is a principal goal, and treatment strategies aim to do this. The threshold of 30\% predicted for forced expiratory volume in one second should no longer be considered in isolation as the start of end stage lung disease and consideration for lung transplantation. The reasons for the improvement in survival are almost certainly multifactorial, but providing a multidisciplinary approach, with attention to details such as nutrition and airway clearance, is likely to be a key element in maintaining health even at low levels of lung function. In conclusion, we have shown that the survival of patients with cystic fibrosis whose lung function 


\section{WHAT IS ALREADY KNOWN ON THIS TOPIC}

A forced expiratory volume in one second $\left(\mathrm{FEV}_{1}\right)$ below $30 \%$ of the predicted value is generally considered the threshold at which $50 \%$ of patients with cystic fibrosis survive two years or less

Modern cystic fibrosis management over the past two decades may have led to improved outcomes, but this has not been shown in patients with severely impaired lung function

Certain clinical factors, such as a higher body mass index, are associated with better outcomes

\section{WHAT THIS STUDY ADDS}

Median survival of patients with cystic fibrosis and $\mathrm{FEV}_{1}$ below $30 \%$ increased from 1.2 years in the 1990-1 sub-cohort to 5.3 years in the 2002-3 sub-cohort

A clear stepwise improvement from 1994 to 1997 (with little further change thereafter) coincided with the introduction of nebulised recombinant human DNase

A steady improvement in body mass index also occurred; body mass index below 19 was associated with an increased risk of death
3 Kerem E, Reisman J, Corey M, Canny GJ, Levison H. Prediction of mortality in patients with cystic fibrosis. N Engl / Med 1992;326:1187-91.

4 Orens JB, Estenne M, Arcasoy S, Conte JV, Corris P, Egan JJ, et al. International guidelines for the selection of lung transplant candidates: 2006 update-a consensus report from the Pulmonary Scientific Council of the International Society for Heart and Lung Transplantation. J Heart Lung Transplant 2006;25:745-55.

5 Liou TG, Adler FR, Cahill BC, Fitzsimmons SC, Huang D, Hibbs JR, et al. Survival effect of lung transplantation among patients with cystic fibrosis. JAMA 2001;286:2683-9.

6 Corey M, Farewell V. Determinants of mortality from cystic fibrosis in Canada, 1970-1989. Am J Epidemiol 1996;143:1007-17.

7 Steinkamp G, Wiedemann B. Relationship between nutritional status and lung function in cystic fibrosis: cross sectional and longitudinal analyses from the German CF quality assurance (CFQA) project. Thorax 2002;57:596-601.

8 Ramsey BW, Dorkin HL, Eisenberg JD, Gibson RL, Harwood IR, Kravitz RM, et al. Efficacy of aerosolized tobramycin in patients with cystic fibrosis. N Engl/ Med 1993;328:1740-6.

9 Fuchs HJ, Borowitz DS, Christiansen DH, Morris EM, Nash ML, Ramsey BW, et al. Effect of aerosolized recombinant human DNase on exacerbations of respiratory symptoms and on pulmonary function in patients with cystic fibrosis. $N$ Engl J Med 1994;331:637-42

10 Elkins MR, Robinson M, Rose BR, Harbour C, Moriarty CP, Marks GB et al. A controlled trial of long-term inhaled hypertonic saline in patients with cystic fibrosis. N Engl J Med 2006;354:229-40.

declines below $30 \%$ of predicted has improved markedly, with a median predicted survival now of 5 . 3 years. This finding will help to inform patients and relatives, assist clinicians in managing their individual patients appropriately, and inform policy makers on timing of interventions with implications on resource allocation.

The study was supported by the Respiratory Biomedical Research Unit (BRU) at the Royal Brompton Hospital; MEH, DB, and NJS are part of the Chronic Suppurative Lung Disease (CSLD) research consortium of the Respiratory BRU. We acknowledge the input of Khin Gyi for supporting the data collection process that proved invaluable to the study. Contributors: PMG contributed to conception and design, acquisition of data, analysis and interpretation of data, drafting the article, and final approval of the version to be published. WB contributed to design, statistical analysis and interpretation of data, and final approval of the version to be published. NP contributed to design, acquisition and analysis of data, and final approval of the version to be published. DB contributed to the conception, design, analysis and interpretation of the data, and final approval of the version to be published. PC contributed to design, statistical analysis and interpretation of data, drafting the article, and final approval of the version to be published. MEH contributed to conception and design, analysis and interpretation of data, and final approval of the version to be published. NJS contributed to conception and design, acquisition of data, analysis and interpretation of data, drafting the article, and coordinating the study. NJS is the guarantor. Funding: No external funding.

Competing interests: All authors have completed the Unified Competing Interest form at www.icmje.org/coi_disclosure.pdf (available on request from the corresponding author) and declare that they have no relationships with any company that might have an interest in the submitted work in the previous 3 years; nor do their spouses, partners, or children have any financial relationships that may be relevant to the submitted work; and they have no non-financial interests that may be relevant to the submitted work.

Ethical approval: The Royal Brompton Hospital Ethics Committee has approved use of the data for this purpose.

Data sharing: No additional data available.

1 Elborn JS, Shale DJ, Britton JR. Cystic fibrosis: current survival and population estimates to the year 2000. Thorax 1991;46:881-5.

2 Hodson ME, Simmonds NJ, Warwick WJ, Tullis E, Castellani C, Assael B, et al. An international/multicentre report on patients with cystic fibrosis (CF) over the age of 40 years. J Cyst Fibros 2008;7:537-42.

11 Saiman L, Marshall BC, Mayer-Hamblett N, Burns IL, Quittner AL, Cibene DA, et al. Azithromycin in patients with cystic fibrosis chronically infected with Pseudomonas aeruginosa: a randomized controlled trial. JAMA 2003;290:1749-56.

12 Shah PL, Scott SF, Fuchs HJ, Geddes DM, Hodson ME. Medium term treatment of stable stage cystic fibrosis with recombinant human DNase I. Thorax 1995; 50:333-8.

13 Madden BP, Kariyawasam H, Siddiqi AJ, Machin A, Pryor JA, Hodson ME. Noninvasive ventilation in cystic fibrosis patients with acute or chronic respiratory failure. Eur Respir / 2002;19:310-3.

14 Mahadeva R, Webb K, Westerbeek RC, Carroll NR, Dodd ME, Bilton D, et al. Clinical outcome in relation to care in centres specialising in cystic fibrosis: cross sectional study. BMJ 1998;316:1771-5.

15 Milla CE, Warwick WJ. Risk of death in cystic fibrosis patients with severely compromised lung function. Chest 1998;113:1230-4

16 Doershuk CF, Stern RC. Timing of referral for lung transplantation for cystic fibrosis: overemphasis on FEV1 may adversely affect overall survival. Chest 1999;115:782-7.

17 Gibson GJ. Standardised lung function testing. Eur Respir J 1993;6:155-7.

18 UK Cystic Fibrosis Trust Nutrition Working Group. Nutritional management of cystic fibrosis. Cystic Fibrosis Trust, 2002.

19 Paul K, Rietschel E, Ballmann M, Griese M, Worlitzsch D, Shute J, et al. Effect of treatment with dornase alpha on airway inflammation in patients with cystic fibrosis. Am J Respir Crit Care Med 2004;169:719-25.

20 Jones AP, Wallis C. Dornase alfa for cystic fibrosis. Cochrane Database Syst Rev 2010;3:CD001127.

21 Quan JM, Tiddens HA, Sy JP, McKenzie SG, Montgomery MD, Robinson PJ, et al. A two-year randomized, placebo-controlled trial of dornase alfa in young patients with cystic fibrosis with mild lung function abnormalities. J Pediatr 2001;139:813-20.

22 Mischler EH, Parrell S, Farrell PM, Odell GB. Comparison of effectiveness of pancreatic enzyme preparations in cystic fibrosis. Am J Dis Child 1982;136:1060-3.

23 Emerson J, Rosenfeld M, McNamara S, Ramsey B, Gibson RL. Pseudomonas aeruginosa and other predictors of mortality and morbidity in young children with cystic fibrosis. Pediatr Pulmonol 2002;34:91-100.

24 Finkelstein SM, Wielinski CL, Elliott GR, Warwick WJ, Barbosa J, Wu SC, et al. Diabetes mellitus associated with cystic fibrosis. Pediatr 1988;112:373-7.

25 Milla CE, Billings J, Moran A. Diabetes is associated with dramatically decreased survival in female but not male subjects with cystic fibrosis. Diabetes Care 2005;28:2141-4.

26 Rosenfeld M, Davis R, FitzSimmons S, Pepe M, Ramsey B. Gender gap in cystic fibrosis mortality. Am J Epidemiol 1997;145:794-803.

27 Wark P, McDonald VM. Nebulised hypertonic saline for cystic fibrosis. Cochrane Database Syst Rev 2009;2:CD001506.

28 Calverley PM, Anderson JA, Celli B, Ferguson GT, Jenkins C, Jones PW, et al. Salmeterol and fluticasone propionate and survival in chronic obstructive pulmonary disease. N Engl/ Med 2007;356:775-89.

Accepted: 31 December 2010 